\title{
Letter \\ Osteoactivin/HGFIN: is it a tumor suppressor or mediator of metastasis in breast cancer?
}

April AN Rose ${ }^{1}$ and Peter M Siegel ${ }^{1,2,3}$

\author{
1'Department of Medicine, McGill University, Montreal, Quebec, Canada \\ ${ }^{2}$ Department of Biochemistry, McGill University, Montreal, Quebec, Canada \\ ${ }^{3}$ Department of Anatomy and Cell Biology, McGill University, Montreal, Quebec, Canada
}

Corresponding author: Peter M Siegel, peter.siegel@mcgill.ca

Published: 27 November 2007

This article is online at http://breast-cancer-research.com/content/9/6/403

(c) 2007 BioMed Central Ltd

See related research article by Metz et al., http://breast-cancer-research.com/content/9/5/R58
Breast Cancer Research 2007, 9:403 (doi:10.1186/bcr1791)
In the previous issue of Breast Cancer Research, Metz and colleagues characterize hematopoietic growth factor inducible neurokinin-1 type (HGFIN; osteoactivin, Gpnmb, Dc-HIL) as a gene expressed in normal mammary epithelial cells that encodes a protein with tumor suppressor functions in breast cancer [1]. In contrast, we have recently identified osteoactivin as a novel mediator promoting breast cancer metastasis [2] and thus feel it is premature to classify osteoactivin as a tumor suppressor in breast cancer.

In their article, Metz et al. claim that osteoactivin expression is "detectable in non-tumorigenic cells, but low to undetectable in malignant cells". This conclusion was based on RNA expression in three breast cell lines and three primary breast tissues. In our study, we analyzed microarray data from a recently published data set [3] that examined gene expression profiles of three non-malignant and 51 malignant human breast cell lines. We confirmed these microarray data by performing quantitative real-time polymerase chain reaction (PCR) of osteoactivin expression in nine of these cell lines [2]. Our analysis revealed that 48 of the 51 breast cancer cell lines examined possessed higher osteoactivin expression than normal breast MCF-12A cells. In contrast to the data from Metz et al., the T47D and HCC70 breast cancer cell lines possessed 2.4 and 48.5 fold higher osteoactivin expression, respectively, relative to MCF-12A cells.

The authors also performed in situ hybridization for osteoactivin mRNA in paraffin embedded breast biopsies. They conclude that osteoactivin is found at higher levels in benign tissues than in malignant tissues, and that no correlation exists between osteoactivin expression and estrogen recep- tor (ER) status. It must be noted that their conclusions are in contrast to several published large scale analyses of primary human breast tumors that are available through the online cancer microarray database, Oncomine [4]. These studies indicate that osteoactivin expression is significantly higher in both breast cancer versus normal breast specimens and in ER negative versus ER positive breast tumors [2].

Metz et al. state: "Osteoactivin is expressed in breast cancer cells and has been associated with bone invasion, and aggressive form of the tumor". They repeatedly refer to Rich et al. to corroborate this remark, however, this particular reference does not provide any evidence to support this statement [5]. Rich et al. were, in fact, investigating a role for osteoactivin in promoting the invasion of a defined glioma model. This study did not employ breast cancer cells in any experiments, nor was bone metastasis investigated. In our study, we report, for the first time, that ectopic osteoactivin expression in breast cancer cells is sufficient to induce a significant increase in the incidence of osteolytic bone metastases in vivo.

Finally, Metz et al. refer to a study that links osteoactivin expression to the low metastatic potential of melanoma cell lines to support the notion that osteoactivin functions as a tumor suppressor [6]. However, the authors have overlooked more recent studies that identify osteoactivin as being highly expressed in metastatic melanoma-derived cell lines and clinical specimens. These studies report the development of a cytotoxin-conjugated, anti-osteoactivin antibody (CR011-vcMMAE) that is currently in Phase I/II clinical trials as a treatment for patients with Stage III and Stage IV melanoma [7,8].

HGFIN = hematopoietic growth factor inducible neurokinin-1 type; Gpnmb = Glycoprotein (transmembrane) nmb; Dc-HIL = dendritic cell heparin integrin ligand; $\mathrm{ER}=$ estrogen receptor; $\mathrm{PCR}=$ polymerase chain reaction. 
In summary, osteoactivin is emerging as an important, yet controversial effector of tumor progression in several cancer types, including breast. As such, the pursuit of rigorous, functional studies - aimed at addressing the mechanisms of osteoactivin-mediated effects on tumor progression and metastasis in vivo - will be critical to assess its feasibility as a target for therapeutic intervention in breast cancer.

\section{Competing interests}

The authors declare that they have no competing interests.

\section{References}

1. Metz RL, Patel PS, Hameed M, Bryan M, Rameshwar P: Role of human HGFIN/nmb in breast cancer. Breast Cancer Res 2007, 9:R58.

2. Rose AAN, Pepin F, Russo C, Abou Khalil JE, Hallett M, and Siegel PM: Osteoactivin promotes breast cancer metastasis to bone. Mol Cancer Res 2007 5:1001-1014.

3. Neve RM, Chin K, Fridlyand J, Yeh J, Baehner FL, Fevr T, Clark L, Bayani N, Coppe J-P, Tong F, et al:: A collection of breast cancer cell lines for the study of functionally distinct cancer subtypes. Cancer Cell 2006 10:515-527.

4. Oncomine - Cancer Profiling Database [http://www.oncomine. org]

5. Rich JN, Shi Q, Hjelmeland M, Cummings TJ, Kuan C-T, Bigner $\mathrm{DD}$, Counter CM, Wang X-F: Bone-related genes expressed in advanced malignancies induce invasion and metastasis in a genetically defined human cancer model. J Biol Chem 2003 278:15951-15957.

6. Weterman MA, Ajubi N, van Dinter IM, Degen $\mathrm{WH}$, van Muijen GN, Ruitter DJ, Bloemers HP: nmb, a novel gene, is expressed in low-metastatic human melanoma cell lines and xenografts. Int J Cancer 1995 60:73-81.

7. Tse KF, Jeffers M, Pollack VA, McCabe DA, Shadish ML, Khramtsov NV, Hackett CS, Shenoy SG, Kuang B, Boldog FL, et al.: CR011, a fully human monoclonal antibody-auristatin $E$ conjugate, for the treatment of melanoma. Clin Cancer Res 2006 12:1373-1382.

8. Pollack VA, Alvarez E, Tse KF, Torgov MY, Xie S, Shenoy SG, MacDougall JR, Arrol S, Zhong H, Gerwien RW et al.: Treatment parameters modulating regression of human melanoma xenografts by an antibody-drug conjugate (CR011-vcMMAE) targeting GPNMB. Cancer Chemother Pharmacol 2007 60:423435. 